\title{
Overview of Rheumatic Diseases in the Elderly: The FIBRA Study
}

\section{Panorama das Doenças Reumáticas em Idosos: Estudo FIBRA}

\author{
Sarina Francescato Torres ${ }^{1}$, Anita Liberalesso Neri², Flávia Silva Arbex Borim ${ }^{3}$ \\ ' Physiotherapist. Master's degree student in the post-graduate program in Gerontology at the Faculty of Medical Sciences, State University \\ of Campinas (UNICAMP). <sarinaftorres@gmail.com> \\ 2 Psychologist. Post-graduate co-ordinator and professor in the post-graduate program in Gerontology at the Faculty of Medical Sciences, \\ State University of Campinas (UNICAMP), São Paulo, SP, Brazil. <anitalbn@fcm.unicamp.br> \\ ${ }_{3}^{3}$ Physiotherapist. Professor in the post-graduate program in Gerontology at the Faculty of Medical Sciences, State University of \\ Campinas (UNICAMP), São Paulo, SP, Brazil.<flarbex@hotmail.com>
}

\section{ARTICLE INFO}

\section{Article history}

Received: 22/04/2016

Accepted: 06/06/2016

Correspondent Author

Sarina Francescato Torre

Rua Professor Queiroz Filho, 312

37550-000 Pouso Alegre, MG, Brasil

<sarinaftorres@gmail.com>

\section{(C) 2016 All rights reserved}

\section{Editors}

Alfredo Cataldo Neto

Paula Engroff

\begin{abstract}
Introduction: The high prevalence of rheumatic diseases and the countless adverse effects caused in the individual make them a great challenge for governments and healthcare systems worldwide. Objective: To assess the prevalence of rheumatic diseases in the elderly and their relationship with some biopsychosocial variables. Method: This is a cross-sectional population-based study whose data were obtained from the FIBRA Study electronic database, developed in the 2008-2009 period and involving 2,593 individuals older than 65 years who lived in urban areas. Results: We found that rheumatic diseases have a prevalence of $43.5 \%$ in the elderly sample, with mean age of 72.3 years old and predominance of females. The biopsychosocial variables more strongly associated with rheumatic diseases were: chronic diseases (52.1\%); depressive symptoms (56.7\%); regular (48.5\%), poor or very poor (52.3\%) health self-evaluation; report of one (49.7\%) or more $(62.7 \%)$ cases of falls; and obesity (57.0\%). Conclusion: We found a high prevalence of rheumatic diseases in the elderly population and a close relationship of these with the individual's biopsychosocial variables, and given the world population ageing, the scenario is worsened in the public healthcare and thus strategies for prevention and early treatment of these diseases should be implemented urgently.
\end{abstract}

KEYWORDS: Rheumatic diseases; Osteoarthritis; Arthritis; Elderly; Epidemiology.

\section{RESUMO}

Introdução: A alta prevalência de doenças reumáticas e os inúmeros efeitos adversos causados no indivíduo as tornam um grande desafio para os governos e para os sistemas de saúde em todo o mundo. Objetivo: Avaliar a prevalência de doenças reumáticas em idosos e sua relação com algumas variáveis biopsicossociais. Método: Estudo transversal de base populacional, cujos dados foram provenientes do banco eletrônico do Estudo de Fragilidade em Idosos Brasileiros (FIBRA), realizado entre os anos de 2008-2009, em que foram recrutados 2.593 idosos da comunidade residentes na área urbana, com idade $\geq 65$ anos. Resultados: Verificamos uma prevalência de 43,5\% de doenças reumáticas nos idosos estudados, cuja média de idade foi de 72,3 anos, com predominância do sexo feminino e de idosos com 5 a 8 anos de escolaridade. As variáveis biopsicossociais mais fortemente associadas com as doenças reumáticas foram as doenças crônicas $(52,1 \%)$; sintomas depressivos $(56,7 \%)$; autoavaliação de saúde regular (48,5\%), ruim ou muito ruim (52,3\%); relato de uma $(49,7 \%)$ ou mais $(62,7 \%)$ quedas; e obesidade $(57,0 \%)$. Conclusão: Encontramos uma alta prevalência de doenças reumáticas na população idosa e uma estreita relação desta com variáveis biopsicossociais do indivíduo, o que, somado ao crescente envelhecimento da população mundial, evidencia a urgência na implementação de estratégias de prevenção e tratamento precoce dessas doenças nos idosos.

PalaVRAS-CHAVE: Doenças reumáticas; Osteoartrite; Artrite; Idoso; Prevalência. 


\section{INTRODUCTION}

There are more than 100 diseases classified as rheumatic, with Osteoarthritis (OA) and Rheumatoid Arthritis (RA) being the most prevalent in the elderly population and both being chronic and characterised by moderate to intense pain, oedema, joint rigidity, muscle weakness, among other signs and symptoms ${ }^{1-3}$.

Far beyond the physical damages affecting the carriers of these diseases are emotional, social and financial harms, since rheumatic diseases have seen associated with depressive symptoms, reduced family life, decrease in daily life, religious, leisure activities, and increase in the number of medical licenses, including labour absenteeism, loss of productivity and job abandonment ${ }^{4,5}$.

Although there are several studies investigating the prevalence of rheumatic diseases, only a few ones address this issue in the elderly population. Furthermore, up to now there is no study aimed to understand the relationship of these diseases with aged individual's biopsychosocial variables in an attempt to establish their repercussion to the individual and society. This work seeks to understand the context of rheumatic diseases in the elderly individual by investigating their both prevalence and related factors.

\section{MATERIAL \& METHODS}

This is a cross-sectional population-based study of 2,593 elderly subjects, whose data were obtained from the FIBRA (Frailty in Brazilian Elderly) electronic database, which was developed in the 2008-2009 period, with support by the National Council for Scientific Research $(\mathrm{CNP} q)$. All the subjects were 65 years of age or older and had been recruited from urban areas.

The present study was approved by the local ethics research committee of the State University of Campinas (CAAE 49730615.5.0000.5404) according to protocol number 208/2007 of FIBRA Network Project.

\section{The FIBRA Network}

Elderly males and females were included in the study and then divided into four groups by age: 65-69, $70-74,75-79$ and 80 years or older. The cities whose data were used in this work are: Campinas (São Paulo), Belém (Pará), Parnaíba (Piauí), Campina Grande (Paraíba), Poços de Caldas (Minas Gerais), Ivoti (Rio Grande do Sul) and Ermelino Matarazzo (São Paulo).

The minimum number needed to form a sample for cities with more than 1 million people (e.g. Campinas and Belém) was of 601 subjects, considering a sampling error of $4 \%$. The other cities with less than 1 million people, samples of 385 subjects were estimated for a sampling error of $5 \%$.

A two-stage conglomerate sampling was performed for conducting this study. In the first stage, urban census sectors of the participating cities were selected by draw. In the second stage, the aged individuals were recruited at their homes by identified and trained personnel, who followed a presentation protocol to explain the research and invite them. The objective of the recruiters was to identify elderly individuals who could meet the following inclusion criteria: to understand the instructions; to accept to participate in the study; to dwell permanently in the place and census sector; and to be older than 65 years old. The following elderly individuals were excluded from the study: those who presented deficits in memory, attention, communication, spatial and temporal orientation functions; cognitive impairment; permanent or temporary disability to walk (except those using gait assistive devices); localised loss of strength and aphasia resulting from cerebrovascular accidents (CVA); severe impairment of movements, speech or affection associated with advanced Parkinson's disease; severe deficits in hearing and vision and/or being terminally-ill.

\section{Data Collection}

Data were collected during single meetings lasting from 40 to 120 minutes in which the elderly individuals were told about the research purposes, and if they agreed to participate then they had to sign an informed consent form.

In the first phase of the data collection, the elderly subjects underwent blood pressure and anthropometric measurements, with frailty, demographic and socioeconomic variables being evaluated as well. Minimental state exam (MMSE) ${ }^{6}$ was used for cognitive evaluation, with those scoring below the cut-off being excluded before completing the questionnaire. The cut-off points were 17 for illiterate subjects, 22 for subjects with $1-4$ years of schooling, 24 for subjects with 5-8 years of schooling and 26 for those with 9 or more years of schooling. These cut-offs were based on the criteria suggested by the Brazilian Academy of Neurology, published by Brucki et al.(') minus a standard deviation.

In the second phase, the elderly subjects scoring above the cut-off points in the MMSE were asked to complete a self-report assessment of physical health, functionality, depressive symptoms, life satisfaction, chronic diseases (signs and symptoms), sleep problems, falls and fractures, use of medications, smoking and drinking, access to medical and hospital services in the past year (Figure 1). 


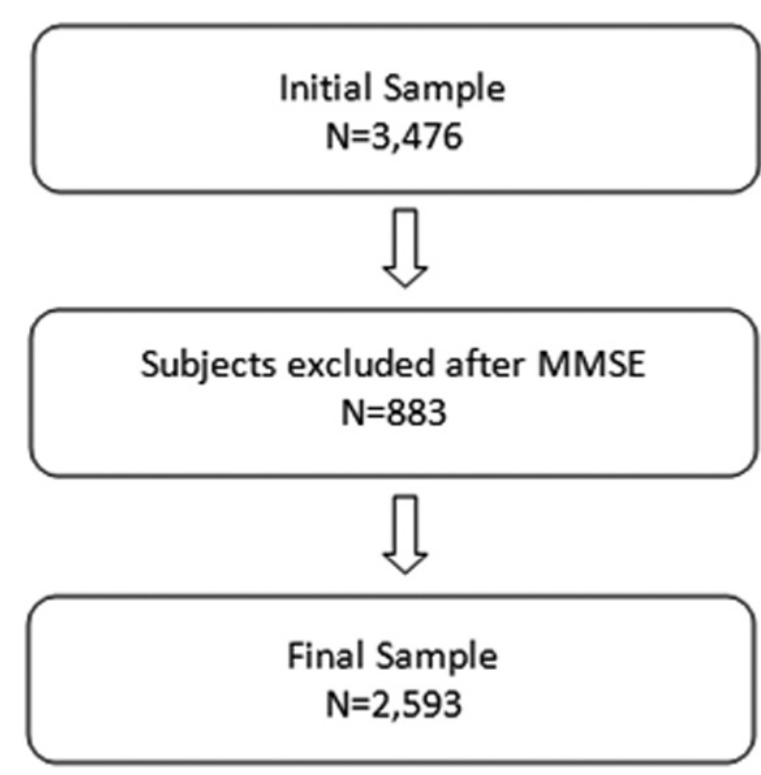

Figure 1. Study sample flowchart.

\section{Instruments for Data Collection}

The variables analysed in the present study were the following:

a) Rheumatic disease was identified by asking "Has any doctor told you that you have arthritis or rheumatism?" The subject had to answer yes or no.

b) Demographic characteristics were gender and age group (65-69, 70-74, 75-79 and 80 years or older).

c) Socioeconomic characteristics were education level, which was grouped according to the years of schooling (never studied, 1-4 years, 5 years or more), and per capita monthly family income, which was divided into the following income ranges: above 5 minimum salaries, 5 to 3.1 salaries, 3 to 1.1 salaries, and below or equal to 1 salary.

d) Number of chronic diseases was identified by asking "Has any doctor told you that you have some of the following chronic diseases: systemic blood pressure, diabetes mellitus, heart disease, CVA/ischemia/stroke, cancer, lung diseases or osteoporosis?" The subject could answer yes or no for each disease. In the end, the results were grouped into two ranges: none to two diseases and three or more diseases.

e) Functional capacity was evaluated through selfreport by the subjects regarding Instrumental Activities in the Daily Living (IADLs) and Basic Activities in the Daily Living (BADLs), with those reporting the need of partial or total assistance for performing one or more IADLs and BADLs being considered dependent according to the following scales:

I - The Lawton Instrumental Activities of Daily Living (IADL) scale:8,9 This scale assesses the assistance needed to perform seven IADL items, namely: to telephone, to use transportation, to make purchases, to cook, to use medication and to handle money. The elderly subject should answer whether he or she was fully independent as well as whether he or she needed some or full assistance to perform each one of these activities.

II - Katz Index of Independence in Activities of Daily Living (BADL) scale: ${ }^{10,11}$ This scale assesses the assistance needed to perform six self-care BADLs (basic): to feed, to control sphincter, to displace, to perform personal hygiene, to dress oneself and to bath oneself. The elderly subject was asked whether he or she was fully independent as well as whether he or she needed some or full assistance to perform each one of these activities.

f) Social involvement was evaluated through self-report by the subjects regarding Advanced Activities in the Daily Living (AADLs). We used a previously tested questionnaire with items on participation in the following activities: to make visits; to go to church or social meetings; to frequent cultural events; to drive a car; and to attend third age universities and/or community groups for the elderly. The answer might be "never did", "stopped doing", and "still do". Items whose answer was "still do" were scored, with maximum score of 6 points. The results were divided into the following ranges of AADLs: 0 to 2 activities maintained, 3 activities maintained, and 4 to 6 activities maintained; which evidenced the degree of social development of the elderly subjects.

g) Waist-hip Ratio (WHR) was calculated by dividing the waist circumference $(\mathrm{cm})$ by the hip circumference $(\mathrm{cm})$, with the result being classified according to criteria proposed by Lohman et al., ${ }^{(12)}$ in which the risk of metabolic complications associated with obesity was rated as low, moderate or high.

h) Body Mass Index (BMI) was obtained by using the following formula: weight $(\mathrm{kg})$ divided by the square of the height $(\mathrm{cm})$. For classification of the nutritional state, we followed the recommendations set by the PanAmerican Health Organisation (PAHO), which established the following ranges for the elderly: 
- $\mathrm{BMI}<23$ = low weight;

- BMI 23 to 27.99 = eutrophic;

- BMI 28 to 29.99 = overweight;

- $\mathrm{BMI} \geq 30$ = obesity.

i) Depressive symptom was obtained by using the Geriatric Depression Scale (GDS) version ${ }^{(13,14)}$ consisting of 15 items which indicate absence or presence of symptoms of changes in mood in the past week, allowing dichotomous answers only (i.e. yes or no). Those elderly subjects scoring 6 points or more were considered as having depressive symptoms.

j) Health self-report was obtained by asking "In general, would you say that your health is: excellent, very good, regular, poor or very poor?" The results were rated into 3 groups: excellent/very good, regular, and poor/very poor.

k) Frailty was evaluated through indicators proposed by Fried et al. ${ }^{15}$ as follows:

I - Unintentional weight loss was evaluated by asking "Have you lost weight unintentionally in the past 12 months?" In case of affirmative answer, it was asked how many kilos the subject had lost, with cut-off of $4.5 \mathrm{~kg}$ or $5 \%$ body weight.

II - Fatigue was evaluated through self-report based on 2 questions from the Centre of Epidemiological Studies on Depression (CES-D), ${ }^{(16)}$ validated for Brazil ${ }^{17}$. The first question was: "Have you felt that you had to make an effort to do your usual tasks?" The second question was: "Haven't you managed to do your things?" Each one allowed the following answers: never/seldom; a few times; most of the time; always. Only those subjects answering "always" or "most of the time" and one of two questions scored for fatigue.

III - Grip strength was evaluated with a portable hydraulic hand dynamometer (JAMAR, Lafayette Instruments Inc.). The values obtained were recorded in kgf. The elderly subject should be seated with the dominant arm flexed at 90-degree angle in relation to the forearm. Then he or she was asked to press the device's lever as much as possible, relaxing the hand after reaching the maximum peak force. This task was repeated three times with 1-minute interval between them. Low grip strength was defined as the mean of the 3 values obtained, adjusted by gender and $\mathrm{BMI}$ according to the ranges recommended by the World Health Organisation (WHO), cited by Marucci \& Barbosa ${ }^{18}$.

IV - Gait Slowness was evaluated with the elderly subject walking a distance of $4.6 \mathrm{~m}$ at his or her usual speed. Two 2-metre long lines were added before and after the trajectory, with the first being used for acceleration and the second for deceleration. The subject was allowed to use his or her gait assistive device (e.g. walking frame or cane) in the task. Three attempts were made and timed for each trajectory by using a hand stopwatch. The times for acceleration and deceleration (2 metres each) were not recorded. Values above the $80^{\text {th }}$ percentile of time spent (20 percent higher) by the subjects to complete 4.6 metres indicated low gait speed. These values were recorded in seconds and calculated as the mean of the three measures taken and then adjusted by height median for both males and females (males: $0<$ height $\leq 1.68$, Cut-off point $\leq 5.49$; height $>1.68$, Cut-off point $\leq 5.54$; females: $0<$ height $\leq 1.55$, Cut-off point $\leq 6.61$; height $>1.55$, Cut-off point $\leq 5.92$ ).

$\mathrm{V}$ - Physical inactivity evaluated through selfreport on weekly practice of physical exercises (e.g. walking, climbing stairs, cycling, ballroom dancing, gym and stretching, hydrogymnastics, running, bodybuilding, swimming, and other sporting activities) and domestic tasks (e.g. cleaning, cooking and housekeeping) based on the Minnesota Leisure Time Physical Activity Questionnaire (MLTPAQ), validated to Brazil ${ }^{19}$. Each of the activities corresponded to an intensity measure expressed in metabolic equivalent (MET), which indicated the individual's weekly energy expense. Those subjects scoring below the first quintile were considered inactive.

At the end of all evaluations, the elderly subjects were rated as non-frail when they had no score, pre-frail when they scored on one or two criteria, and frail when they scored on three or more criteria.

1) Fall stories were obtained through self-report by asking "Over the last 12 months, have you fallen?" In affirmative case, it was asked about how many times it had occurred.

\section{Data Analysis}

Data on the elderly subjects were entered into the database and two trained raters checked the consistency of the information, which required 100-percent concordance for acceptance of the records. "Arthritis or other rheumatic disease" was considered the dependent variable, whereas the others considered independent. Percentage distributions and respective 95\% confidence intervals were estimated for analyses. 


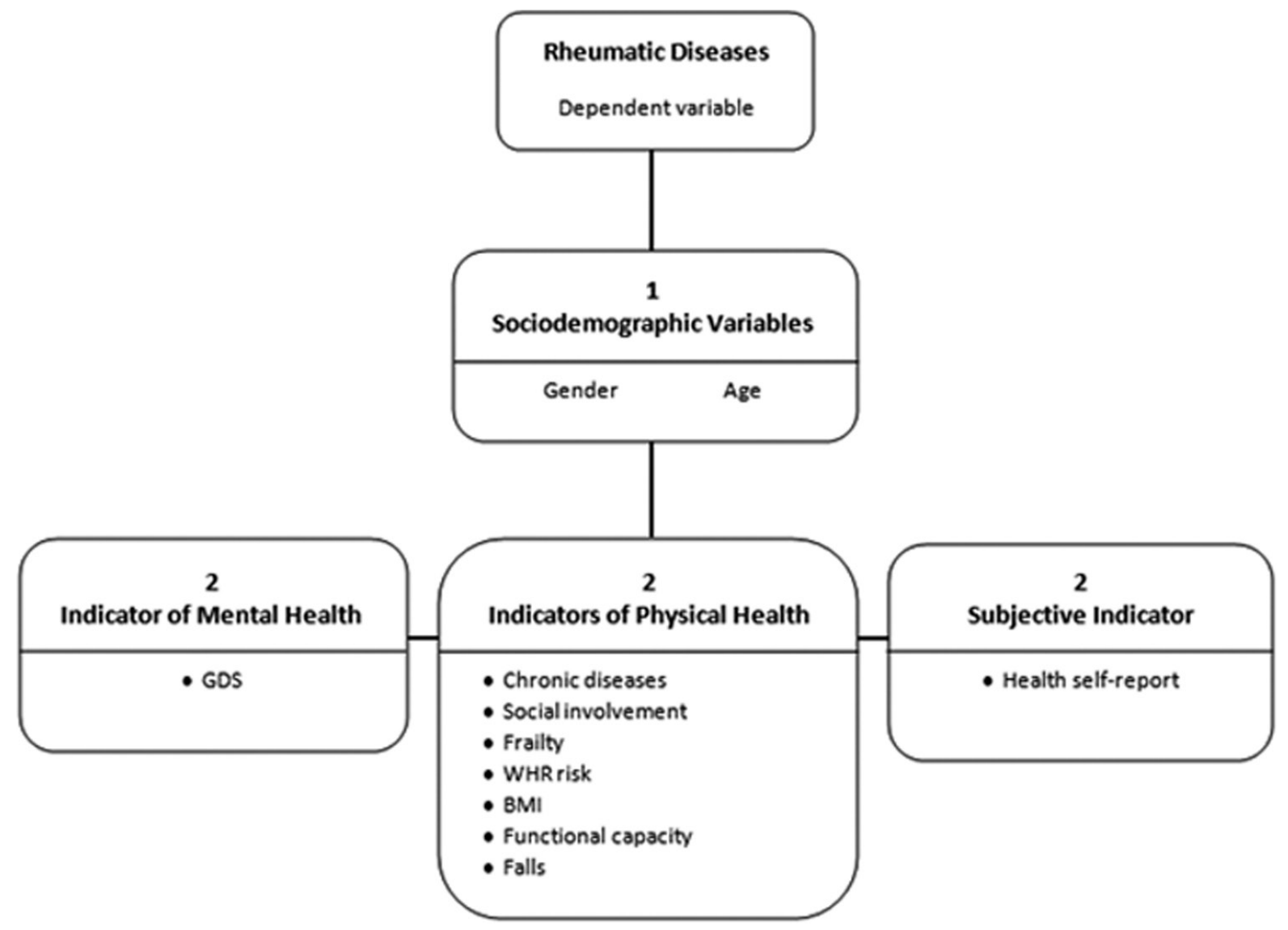

Figure 2. Hierarchical model for data analysis.

The associations between independent variables and rheumatic diseases were analysed by using the Pearson's chi-square test at significance level of 5\%. Poisson regression analyses (simple and multiple) were also used to estimate both gross and adjusted prevalence ratios. Variables with significance level below 20\% $(p \leq 0.20)$ were introduced into the Poisson multiple regression model and in the relationship with the dependent variable, remaining in the model only those with $p \leq 0.05$. The regression model was developed in two steps. In the first step, sociodemographic variables were introduced, whereas indicators of physical health, mental health and the indicator of subjective health were added in the second step (Figure 2).

Data analyses were performed by using the Stata software version 11.0.

\section{RESULTS}

In this study we have analysed data from 2,593 elderly individuals, whose mean age was 72.3 years old $(95 \% \mathrm{CI}$ : $72.1-72.5)$ and $65.9 \%$ were female. The prevalence of rheumatic diseases was $43.5 \%$ (95\% CI: 41.6-45.4). In Table 1 can observe a higher prevalence of self-reported rheumatic diseases among female subjects (52.5\%).
As one can observe in Table 2, the categories of health conditions presenting statistically significant prevalence of rheumatic diseases were the following: presence of three or more chronic diseases (52.1\%); dependent to functional capacity (46.5\%); elderly subjects with depressive symptoms (56.7\%) reporting their health as regular $(48.5 \%)$, poor or very poor $(52.3 \%)$; fragile elderly $(54.8 \%)$; report of one (49.7\%) or more $(62.7 \%)$ episodes of fall, and high risk between waist-hip ratio $(48.1 \%)$ and their categories of reference. With regard to BMI, elderly subjects with low weight had less prevalence $(33.6 \%)$ compared to other categories.

The use of the hierarchical multiple regression model showed that prevalence of rheumatic diseases was higher in women $(P R=2.00)$. Higher prevalence ratios were also observed in elderly individuals with 3 or more chronic diseases, those with depressive symptoms, those reporting their health as being regular or poor/ very poor, and those reporting 1 or more episodes of fall compared to the their reference categories. Increase in body weight was also positively associated with a progressive prevalence of rheumatic diseases. Obese individuals showed a $\mathrm{PR}=1.49$ (95\% CI: 1.28-1.73) compared to those with low weight (Table 3). 
Table 1. Percentage distribution, prevalence and prevalence rate (PR) of arthritis and other rheumatic diseases, according to demographic and socioeconomic variables, in a sample of community elderly individuals (FIBRA - UNICAMP, 2008-2009).

\begin{tabular}{lccc}
\hline \multicolumn{1}{c}{ Variables } & $\mathbf{\%}(\mathbf{n})$ & $\mathbf{\%}$ & PR (IC 95\%) \\
Gender & & $(p<0.001)$ & \\
$\quad$ Male & $34.1(884)$ & 26.2 & 1 \\
Female & $65.9(1.709)$ & 52.5 & $\mathbf{2 . 0 0}(\mathbf{1 . 7 7 - 2 . 2 5})$ \\
Age group (years) & & $(p=0.745)$ & \\
$\quad$ 65-69 & $37.9(982)$ & 43.2 & 1 \\
$70-74$ & $31.2(809)$ & 45 & $1.04(0.93-1.15)$ \\
$75-79$ & $18.9(490)$ & 43.8 & $1.01(0.89-1.14)$ \\
$80-$ older & $12.0(311)$ & 40.4 & $0.93(0.80-1.09)$ \\
Schooling (years) & & $(p=0.746)$ & \\
$\geq 5$ & $30.8(1.065)$ & 43.8 & 1 \\
1-4 & $49.0(1.709)$ & 42.9 & $0.98(0.88-1.08)$ \\
Never studied & $20.2(699)$ & 44.9 & $1.02(0.90-1.16)$ \\
Per capita income (minimum salary) & & $(p=0.374)$ & \\
$>5$ & $18.6(416)$ & 40.1 & 1 \\
$5-3,1$ & $22.0(494)$ & 44.6 & $1.11(0.95-1.29)$ \\
$3,1-1,1$ & $48.4(1.082)$ & 43.1 & $1.07(0.93-1.23)$ \\
$\leq 1$ & $11.0(246)$ & 46.5 & $1.16(0.97-1.38)$ \\
\hline
\end{tabular}

Table 2. Percentage distribution, prevalence and prevalence rate (PR) of arthritis and other rheumatic diseases, according to demographic and socioeconomic variables, in a sample of community elderly individuals (FIBRA - UNICAMP, 2008-2009).

\begin{tabular}{|c|c|c|c|}
\hline Variables & $\%(n)$ & $\%$ & PR \\
\hline Chronic diseases & & $(p<0.001)$ & \\
\hline 0 to 2 & $51.4(1.300)$ & 34.8 & 1 \\
\hline 3 or more & $48.6(1.228)$ & 52.1 & $1.49(1.36-1.63)$ \\
\hline Functional capacity & & $(p=0.023)$ & \\
\hline Independent & $61.8(1.559)$ & 41.8 & 1 \\
\hline Dependent & $38.2(963)$ & 46.5 & $1.11(1.01-1.21)$ \\
\hline Social involvement (AADLs) & & $(p=0.475)$ & \\
\hline 0 to 2 AADLs & $42.6(1.079)$ & 43.5 & 1 \\
\hline 3 AADLs & $24.9(631)$ & 45.4 & $1.04(0.93-1.16)$ \\
\hline 4 to 6 AADLs & $32.5(824)$ & 42.3 & $0.97(0.87-1.08)$ \\
\hline GDS & & $(p<0.001)$ & \\
\hline Without depressive symptom & $79.5(2.025)$ & 40.3 & 1 \\
\hline With depressive symptom & $20.5(521)$ & 56.7 & $1.41(1.28-1.54)$ \\
\hline Health self-report & & $(p<0.001)$ & \\
\hline Excellent/very good & $34.5(881)$ & 31.6 & 1 \\
\hline Regular & $42.4(1.079)$ & 48.5 & $1.53(1.36-1.72)$ \\
\hline Poor/very poor & $23.1(588)$ & 52.3 & 1.65 (1.46-1.87) \\
\hline Frailty & & $(p=0.001)$ & \\
\hline No frailty & $42.4(1.098)$ & 40.7 & 1 \\
\hline Pre-frailty & $50.5(1.308)$ & 44.2 & $1.08(0.98-1.19)$ \\
\hline Frailty & $7.1(182)$ & 54.8 & $1.34(1.15-1.56)$ \\
\hline Number of falls & & $(p<0.001)$ & \\
\hline 0 & $70.6(1.728)$ & 38.5 & 1 \\
\hline 1 & $16.4(402)$ & 49.7 & $1.29(1.15-1.44)$ \\
\hline 2 or more & $13.0(318)$ & 62.7 & $1.62(1.46-1.80)$ \\
\hline WHR risk & & $(p=0.002)$ & \\
\hline Low & $36.6(938)$ & 39.2 & 1 \\
\hline Moderate & $30.1(773)$ & 43.9 & $1.11(0.99-1.25)$ \\
\hline High & $33.3(854)$ & 48.1 & $1.22(1.00-1.36)$ \\
\hline BMI & & $(p<0.001)$ & \\
\hline Low weight & $17.3(444)$ & 33.6 & 1 \\
\hline Eutrophic & $43.3(1.112)$ & 39.5 & $1.17(1.00-1.36)$ \\
\hline Overweight & $14.9(383)$ & 45.5 & $1.35(1.13-1.60)$ \\
\hline Obesity & $24.5(631)$ & 57 & $1.69(1.45-1.96)$ \\
\hline
\end{tabular}


Table 3. Hierarchical multiple regression model (FIBRA - UNICAMP, 2008-2009).

\begin{tabular}{|c|c|c|c|c|c|c|}
\hline \multirow{2}{*}{ Variable } & \multicolumn{3}{|c|}{ First step* } & \multicolumn{3}{|c|}{ Second step* } \\
\hline & PR & IC $95 \%$ & $p$ & PR & IC $95 \%$ & $p$ \\
\hline \multicolumn{7}{|l|}{ Gender } \\
\hline Male & 1 & & & 1 & & \\
\hline Female & 1.98 & $1.76-2.22$ & $<0.001$ & 1.83 & $1.61-2.08$ & $<0.001$ \\
\hline \multicolumn{7}{|l|}{ Chronic diseases } \\
\hline 0 to 2 & & & & 1 & & \\
\hline 3 or more & & & & 1.20 & $1.10-1.32$ & $<0.001$ \\
\hline \multicolumn{7}{|l|}{ GDS } \\
\hline Without depressive symptoms & & & & 1 & & \\
\hline With depressive symptoms & & & & 1.18 & $1.08-1.30$ & $<0.001$ \\
\hline \multicolumn{7}{|l|}{ Health self-report } \\
\hline Excellent/very good & & & & 1 & & \\
\hline Regular & & & & 1.44 & $1.28-1.62$ & $<0.001$ \\
\hline Poor/very poor & & & & 1.43 & $1.26-1.62$ & $<0.001$ \\
\hline \multicolumn{7}{|l|}{ Number of falls } \\
\hline 0 & & & & 1 & & \\
\hline 1 & & & & 1.17 & $1.05-1.30$ & 0.005 \\
\hline 2 or more & & & & 1.28 & $1.15-1.42$ & $<0.001$ \\
\hline \multicolumn{7}{|l|}{ BMI } \\
\hline Low weight & & & & 1 & & \\
\hline Eutrophic & & & & 1.19 & $1.02-1.37$ & 0.020 \\
\hline Overweight & & & & 1.25 & $1.05-1.48$ & 0.010 \\
\hline Obesity & & & & 1.49 & $1.28-1.73$ & $<0.001$ \\
\hline
\end{tabular}

95\% CI: confidence interval of 95\%; PR: prevalence ratio.

* PR adjusted by age.

\section{DISCUSSION}

Despite the fact that self-report for rheumatic diseases has great sensitivity and specificity (around $70 \%),{ }^{(20)}$ these figures are still conflicting as depending on how the authors define such diseases or how the question is formulated, data fluctuate from $12.2 \%$ from $51.9 \%$ of prevalence ${ }^{7,21}$.

Although the prevalence is not specific for the elderly, it was similar to that found in our study as $43.5 \%$ of the subjects reported having one or more rheumatic diseases. With respect to the prevalence of rheumatic diseases in Brazil, the National Sample Survey of Households (PNDA) conducted between 2008 to 2013 showed that self-reported rheumatism was more prevalent among women and over age. ${ }^{(21,22)}$ Our finding corroborates the data from the literature, at least partially, thus evidencing a higher prevalence of rheumatic diseases among women.

The prevalence of rheumatic diseases was $21 \%$ higher in individuals who reported having 3 or more chronic diseases. Recent data point that approximately $70 \%$ of the world's elderly population has multi-morbidities, that is, two or more chronic diseases $^{23}$. The high prevalence of chronic diseases and its relationship with rheumatic diseases show the necessity of multidisciplinary and interdisciplinary treatment.
The great number of aged individuals who report the presence of depressive symptoms in our study is easily explained by the presence of some rheumatic disease, thus making them more susceptible to developing physical and functional disability over time, which may impair their quality of life ${ }^{24}$. The chronic pain itself, resulting from these diseases, favours the emergence of a depressive picture due to the long-lasting suffering caused to the patient, particularly the elderly, who are at higher risk of not following the medical recommendations or not continuing the treatment ${ }^{25}$. Some authors state that the high prevalence of depressive symptoms among rheumatic patients may also be related to the inflammatory character of these diseases, which produces neurochemical and neuroendocrinal alterations in the body, thus favouring the emergence of depressive picture, behavioural changes and cognitive deficits ${ }^{26}$.

This same inflammatory process, which may be involved in the physiopathology of depression, is already established for obesity - a condition increasing progressively in the elderly population ${ }^{27}$. It was found that the increase in body weight is positively associated with rheumatic diseases in aged individuals. It is known for long that body weight causes an overload on some joints and periarticular structures of the body, but there is increasing evidence that obesity is a risk factor contributing mostly to the emergence or impairment 
of rheumatic diseases due to the inflammatory process involved with the increase in body fat ${ }^{28}$.

The combination of ageing with obesity characterises a systemic inflammatory state in which some inflammatory substances (e.g. TNF-a and IL-6) have catabolic effects on the skeletal muscles, which also predisposes to sarcopenic obesity and reduces the physical and functional capacity in this population. (27) This inflammation associated with joint and periarticular degradation provokes a clinical picture characterised by pain, oedema, muscle weakness, reduced movement amplitude, deformity, joint instability and functional impairment, which makes it difficult to perform simple daily activities (e.g. wearing shoes) and consequently decreases the quality of life of the affect individual ${ }^{29}$.

The above-described signs and symptoms seem to justify the fact that a significant number of aged individuals with some rheumatic diseases reported at least one episode of fall. Therefore, rheumatism might be seen as a factor predisposing to falls, as elderly individuals with rheumatic disease are $68 \%$ more likely to suffer falls compared to healthy ones. In addition, $80 \%$ of these individuals develop related lesions and they have 3 times more risk of suffering fractures after falls ${ }^{23,30}$.

Because of all the complications associated with the presence of rheumatic diseases, one can understand why aged individuals with rheumatic diseases reported having regular, poor or very poor health. This health self-perception has been increasingly more used in the research because it yields results similar to those by more objective assessments of health status, in addition to being considered an important predictor of mortality ${ }^{31}$.

On the other hand, we expected that functional capacity was significantly associated with rheumatic diseases, but it did not happen. One of the reasons for this finding could be the fact that the rheumatic subjects were already significantly affected, and this was not assessed in our study since joint radiographs and a specialist physician would be needed to confirm the presence of rheumatic lesion ${ }^{32}$. Regardless of these reasons, it has been already shown that functional incapacity is progressively decreasing over the years because of the greater knowledge on the physiopathology of rheumatic diseases and the improvement of pharmaceuticals and other treatments for such diseases ${ }^{33}$. These recent treatments for rheumatic diseases ${ }^{34}$ have been shown to be very efficient, alleviating the symptoms and improving the quality of life of the affected individuals, which might explain their greater social participation - a finding also demonstrated elsewhere ${ }^{35}$.
In our study, frailty was another variable not significantly related to rheumatic diseases. Some rheumatic diseases (e.g. osteoarthritis) have been already related to a higher incidence of frailty among elderly individuals ${ }^{36}$, but many rheumatic diseases have not yet been studied to assess such a relationship, and because we had included all the rheumatic diseases in our study, this might have contributed to our finding. Furthermore, the close relationship between frailty syndrome and cardiovascular diseases - a variable not analysed separately from other chronic diseases in our work - may have contributed to our results ${ }^{37}$. The lack of association between rheumatic diseases and frailty in our study reinforces the concept that frailty is a yet little-known clinical syndrome.

One limitation in our work, as well as in other population-based studies using self-report data, was to obtain an actual prevalence of certain diseases in the population, as in the case of rheumatic diseases in aged individuals. Other epidemiological studies should be conducted using self-report questionnaires, but also added with medical diagnosis. This is necessary because such information is of fundamental importance of implementing public health care strategies.

\section{CONCLUSION}

The gradual and progressive rise in the number of elderly people and consequently in the cases of rheumatic diseases in this population, in addition to the close relationship between these and some relevant biopsychosocial variables, increases both demand and costs for both health care system and population.

This study showed a high prevalence of rheumatic diseases in elderly and their strong relationship with important biopsychosocial variables, as chronic diseases, depressive symptoms, health self-report, falls and BMI.

Therefore, it becomes clear that the scenario is critical, and there is urgency in investing in socialeducative measures in order to prevent these diseases among the population. Programs and research should also be financially supported for early treatment of rheumatic diseases, mainly in the elderly population.

\section{ACKNOWLEDGEMENTS}

This study received the financial support by the National Council for Scientific Research $(\mathrm{CNPq})$ and by the Coordination for the Improvement of Higher Education Personnel (CAPES), with process number 5550822006-7. 
The authors would like to thank the research agency CAPES for the scholarship to fund Torres SF Master's study.

\section{REFERENCES}

1. Machado GP, Barreto SM, Passos VM, Lima-Costa MF. Health and aging study: prevalence of chronic joint symptoms among the elderly in Bambui. Revista da Associação Médica Brasileira. 2004;50(4):367-72.

2. Fejer R, Ruhe A. What is the prevalence of musculoskeletal problems in the elderly population in developed countries? A systematic critical literature review. Chiropractic \& Manual Therapies. 2012;20(1):1-52.

3. Gibofsky A. Epidemiology, pathophysiology, and diagnosis of rheumatoid arthritis: A synopsis. . The American Journal of Managed Care. 2014;20(7):128-35.

4. Gafvels C, Hagerstrom M, Nordmark B, Wandell P. What predicts negative effects of rheumatoid arthritis? A followup two years after diagnosis. SpringerPlus. 2014;3(118): $1-10$.

5. Blay SL, Fillenbaum GG, Andreoli SB, Gastal FL. Prevalence and concomitants of arthritis in the elderly in Rio Grande do Sul, Brazil. PLoS One. 2012;7 (9):1-7.

6. Folstein MF, Folstein SE, McHugh PR. Mini-mental state. A practical method for grading the cognitive state of patients for the clinician. Journal of Psychiatric Research. 1975;12(3):189-98

7. Brucki SM, Nitrini R, Caramelli P, Bertolucci PH, Okamoto IH. Sugestões para o uso do mini-exame do estado mental no Brasil. Arquivos de Neuro-Psiquiatria. 2003;61(3-B): 777-81.

8. Lawton PM, Brody EM. Assessment of older people: selfmaintaining and instrumental activities of daily living. Gerontologist. 1969;9(3):179-86.

9. Santos RLd, Virtuoso Júnior JS. Confiabilidade da versão brasileira da Escala de Atividades Instrumentais da Vida Diária. Revista Brasileira em Promoção da Saúde. 2008;21:290-6.

10. Katz S, Ford AB, Moskowitz RW, Jackson BA, Jaffe MW. Studies of Illness in the aged the index of ADL: a standardized measure of biological and psychosocial function. JAMA. 1963;185:914-9.

11. Lino VTS, Pereira SRM, Camacho LAB, Ribeiro Filho ST, Buksman S. Adaptação transcultural da Escala de Independência em Atividades da Vida Diária (Escala de Katz). Cadernos de saude publica. 2008;24:103-12.

12. Lohman TG, Roche AF, Martorell R. Anthropometric Standardization Reference Manual. Illinois: Human Kinetics Books. 1988;III.

13. Sheikh JI, Yesavage JA. Geriatric Depression Scale (GDS): recent evidence and development of a shorter version. Clinical Gerontologist. 1986;5(1-2):165-73.

14. Almeida OP, Almeida SA. Confiabilidade da versão brasileira da Escala de Depressão em Geriatria (GDS) versão reduzida. Arquivos de Neuro-Psiquiatria. 1999;57:421-6.

15. Fried LP, Tangen CM, Walston J, Newman AB, Hirsch C, Gottdiener J, et al. Frailty in older adults: evidence for a phenotype. Journal of Gerontology: Medical Sciences. 2001;56(3):146-56.
16. Radloff LS. The CES-D scale: a self-report depression scale for research in the general population. Applied Psychological Measurement. 1977;1(3):385-401.

17. Batistoni SST, Neri AL, Cupertino APFBC. Validade da escala de depressão do Center for Epidemiological Studies entre idosos brasileiros. Revista de Saúde Pública. 2007;41(4):598-605.

18. Marucci MdFN, Barbosa AR. Estado nutricional e capacidade física. In: Lebrão ML, Duarte YAO. SABE - Saúde, Bem estar e Envelhecimento. O Projeto Sabe no município de São Paulo: uma abordagem inicial. Brasília: Organização Pan-Americana da Saúde/MS. 2003. p. $95-117$.

19. Lustosa LP, Pereira DS, Dias RC, Britto RR, Parentoni AN, Pereira LSM. Translation and cultural adaptation of the Minnesota Leisure Time Activities Questionnaire in community-dwelling older people. Geriatria \& Gerontologia. 2011;5(2):57-65.

20. Wibelinger LM, Tombini DK. Perfil epidemiológico dos pacientes atendidos no serviço de fisioterapia reumatológica da universidade de passo fundo. Revista Brasileira de Ciências do Envelhecimento Humano. 2010;7(2): 189-97.

21. Peeters GM, Alshurafa M, Schaap L, de Vet HC. Diagnostic accuracy of self-reported arthritis in the general adult population is acceptable. Journal of Clinical Epidemiology. 2015;68(4):452-9.

22. Costa JO, Almeida AM, Guerra Junior AA, Cherchiglia ML, Andrade EIG, Acurcio FdA. Treatment of rheumatoid arthritis in the Brazilian Unified National Health System: expenditures on infliximab compared to synthetic diseasemodifying anti-rheumatic drugs, 2003-2006. Caderno de Saúde Pública. 2014;30(2):283-95.

23. Sibley KM, Voth J, Munce SE, Straus SE, Jaglal SB. Chronic disease and falls in community-dwelling Canadians over 65 years old: a population-based study exploring associations with number and pattern of chronic conditions. BMC Geriatrics. 2014;14(22):1-11.

24. Miguel RdCC, Dias RC, Dias JMD, Silva SLAd, Menicucci Filho PR, Ribeiro TMS. Síndrome da fragilidade no idoso comunitário com osteoartrite. Revista Brasileira de Reumatologia. 2012;52(3):331-47.

25. Ferreira AH, Godoy PBG, Oliveira NRCd, Diniz RAS, Diniz REAS, Padovani RdC, et al. Investigação da ansiedade, depressão e qualidade de vida em pacientes portadores de osteoartrite no joelho: um estudo comparativo. Revista Brasileira de Reumatologia. 2015;55(5):434-8.

26. Mella LFB, Bértolo MB, Dalgalarrondo P. Depressive symptoms in rheumatoid arthritis patients. Revista Brasileira de Psiquiatria. 2010;32(3):257-63.

27. Santos RR, Bicalho MAC, Mota P, Oliveira DR, Moraes EN. Obesity in the elderly. Revista Médica de Minas Gerais. 2013;23(1):64-73.

28. Berenbaum F. Osteoarthritis as an inflammatory disease (osteoarthritis is not osteoarthrosis!). Osteoarthritis Cartilage. 2013;21(1):16-21.

29. Pisters MF, Veenhof C, Van Dijk GM, Heymans MW, Twisk JW, Dekker J. The course of limitations in activities over 5 years in patients with knee and hip osteoarthritis with moderate functional limitations: risk factors for future functional decline. Osteoarthritis and cartilage/OARS. 2012;20(5):503-10. 
30. Brenton-Rule A, Dalbeth N, Bassett S, Menz HB, Rome $K$. The incidence and risk factors for falls in adults with rheumatoid arthritis: a systematic review. Seminars in arthritis and rheumatism. 2015;44(4):389-98.

31. Pereira LV, Vasconcelos PP, Souza LAF, Pereira GdA, Nakatani AYK, Bachion MM. Prevalence and intensity of chronic pain and self-perceived health among elderly people: a population-based study. Revista Latino-Americana de Enfermagem. 2014;22(4):662-9.

32. Bombardier C, Barbieri M, Parthan A, Zack DJ, Walker V, Macarios $\mathrm{D}$, et al. The relationship between joint damage and functional disability in rheumatoid arthritis: a systematic review. Annals of the Rheumatic Diseases. 2012;71(6): 836-44.

33. Meesters J, Verhoef J, Tijhuis G, Vlieland TV. Functional disability in patients with rheumatoid arthritis admitted for multidisciplinary rehabilitation from 1992 to 2009. Rheumatology. 2013;52:1879-83.
34. Selmi C, Generali E, Massarotti M, Bianchi G, Sciré CA. New treatments for inflammatory rheumatic disease. Immunologic Research. 2014;60(2):277-88.

35. Smolen JS, Braun J, Dougados M, Emery P, FitzGerald O, Helliwell $\mathrm{P}$, et al. Treating spondyloarthritis, including ankylosing spondylitis and psoriatic arthritis, to target: recommendations of an international task force. Annals of the Rheumatic Diseases. 2014;73:6-16.

36. Castell MV, Van der Pas S, Otero A, Siviero P, Dennison E, Denkinger M, et al. Osteoarthritis and frailty in elderly individuals across six European countries: results from the European Project on OSteoArthritis (EPOSA). BMC musculoskeletal disorders. 2015;16(359):1-8.

37. Afilalo J, Alexander KP, Mack MJ, Maurer MS, Green P, Allen LA, et al. Frailty Assessment in the Cardiovascular Care of Older Adults. Journal of the American College of Cardiology. 2014;63(8):747-62. 